\title{
POST-EXTRACTION SOCKET PRESERVATION WITH AUTOGENOUS BONE GRAFT AND HYALURONIC ACID FOLLOWED BY DELAYED IMPLANT PLACEMENT
}

\author{
Rasha A. Taman ${ }^{l} B D S$, Magued H. Fahmy ${ }^{2} P h D$, Sahar Sh. Karam ${ }^{3} P h D$, \\ Adham A. EL Ashwah ${ }^{4} P h D$
}

\begin{abstract}
INTRODUCTION: Alveolar ridge atrophy following tooth extraction remains a challenge for future implant placement. Post-extraction socket preservation and implant placement are two methods that are used to prevent significant post-extraction bone loss.

OBJECTIVES: The aim of this study was to evaluate the role of hyaluronic acid when mixed with autogenous bone graft in alveolar socket preservation for future implant placement.

MATERIALS AND METHODS: A split mouth randomized clinical trial was carried out in 10 patients, 20 mandibular extraction sockets of single rooted teeth with age ranged between $25-55$ years, 10 sockets were grafted with autogenous bone graft only using Auto-Max ${ }^{\mathrm{TM}}$ bone harvester and the other 10 sockets were grafted with autogenous bone graft mixed with hyaluronic acid (Hyadent ${ }^{\mathrm{TM}}$ ).

All sockets were evaluated clinically, radiographically, and histologically (after 2 months, core biopsy was taken before implant placement) then histomophometric analysis and delayed implant insertion were done followed by implant stability assessment. After 4 months, final prosthesis was delivered.

RESULTS: Histological evaluation revealed rapid thick bone deposition with many well organized osteocytes as well as osteoblast lining of the bone surfaces in the study group and increased mean area percent of formed bone. Radiographic bone density changes were found to be statistically significant between the two studied groups. $\left(\mathrm{P}_{2}=<0.001\right)$.

CONCLUSIONS: The use of autogenous bone graft with hyaluronic acid appears to be more efficient in osteoconduction when compared with autogenous bone graft alone and could be a promising strategy for preservation of alveolar sockets.

KEYWORDS: Hyaluronic acid, Autogenous bone graft, Socket preservation, Implant stability.

1- Master student of Oral and Maxillofacial Surgery, Department of Oral and Maxillofacial Surgery, Faculty of Dentistry, Alexandria University, Egypt,
Instructor at Department of Oral and Maxillofacial Surgery, Faculty of Dentistry, Pharos University, Alexandria Egypt.
2- Professor of Oral and Maxillofacial Surgery, Department of Oral and Maxillofacial Surgery, Faculty of Dentistry, Alexandria University, Egypt.
3- Professor of Oral Biology, Department of Oral Biology, Faculty of Dentistry, Alexandria University, Egypt.
4- Assistant Professor of Oral and Maxillofacial Surgery, Department of Oral and Maxillofacial Surgery, Faculty of Dentistry, Alexandria University, Egypt.
\end{abstract}

\section{INTRODUCTION}

Alveolar ridge preservation (ARP) is indicated after teeth extractions to preserve original ridge dimensions and contours, when immediate implant placement is not possible. The techniques for alveolar ridge preservation were introduced in the 1980s using hydroxyapatite in the form of root-shaped cones $(1,2)$. Bone-replacement graft materials have played an important role in regenerative dentistry for many years (3). Today's concept in tooth extraction shall routinely consider maintenance of the existing extraction socket dimensions with some sort of bone-replacement material (4). This procedure has been called ridge preservation (5).

Autogenous bone is often referred to as the gold standard grafting material. Autogenous bone has osteoconductive, osteoinductive and osteogenic properties (6). The advantage of autogenous bone is that it maintains bone structures such as minerals and collagen, as well as viable osteoblasts and Bone Morphogenic Proteins (BMPs) (7).

Bone collectors were proposed many years ago (8), but they have been continuously redesigned, renewed, studied and proposed to achieve the most effective and practical use (9).

Hyaluronic acid (HyA), also known as hyaluronate or hyaluronan, is an endogenous high molecular weight linear polysaccharide of a repeating disaccharide unit that has a number of embryologic and wound healing properties, including the facilitation of cell migration and differentiation during tissue formation and repair (10).

It has been recently reported that HyA increases osteoblastic bone formation in vitro through increased mesenchymal cell differentiation and migration. Locally applied high molecular HyA has also been shown to stimulate differentiation and migration of mesenchymal and muscular cells in vivo. A recently developed formula for autologously prepared HA is expected to provide a potential means of accelerating new bone formation in the morphologic healing of bone wounds (11).

The present study therefore aimed to evaluate clinical, histological and radiographic efficiency of hyaluronic acid "HyA" when combined with autogenous bone graft in filling post-extraction sockets and its effect on implant stability.

\section{MATERIALS AND METHODS}

The ethical clearance was obtained by the ethical committee before the study began, and the selected patients were informed about the nature of the study and the informed consent was obtained.

\section{Patients}

A split mouth randomized clinical trial was conducted on ten patients who were indicated for mandibular bilateral single rooted teeth extraction, they were selected from those admitted to Oral and Maxillofacial Surgery Department, Faculty of Dentistry, Alexandria University. 
Patients were divided in to 2 groups: Study group; Ten extraction sockets of single rooted teeth were grafted with autogenous bone graft using Auto-Max bone harvester combined with hyaluronic acid (Hyadent) and control group; Ten extraction sockets of single rooted teeth of were grafted with autogenous bone graft using Auto-Max bone harvester only.

\section{Inclusion criteria}

Bilateral mandibular single rooted carious teeth indicated for extraction, patients' ages ranged between 25 and 55 years, systemically healthy patients, females were not taking contraceptive pills and adequate oral hygiene, bone quantity as well as adequate inter-occlusal space were included in this study.

\section{Exclusion criteria}

Patients with parafunctional habits such as bruxism and clenching, insufficient inter-occlusal space, insufficient bone volume, medical conditions or medications that might compromise healing or osseointegration such as uncontrolled diabetes mellitus and osteoporosis, poor oral hygiene and habits that might reduce the blood flow and retard healing such as heavy smoking and alcoholism.

\section{Materials}

Twenty Biohorizons Mount-free Tapered Internal dental implants (Birmingham, USA) were placed in the mandibular anterior zone. The implants used in this study were had aggressive buttress threads and anatomically tapered body to provide compressive loading and excellent primary stability.

Two Auto-max bone harvesters (MEGAGEN, Seoul, Korea) of diameters $3.5 \mathrm{~mm}$ and $4 \mathrm{~mm}$ length were used connected with its stopper, mounted on dental engine's handpiece. It is considerd an easy way to harvest autogenous bone, durable, stable drilling with center pin, various diameters are available, autoclavable and can be used up to 5 times.

Ten single use syringes of low molecular weight hyaluronic acid. Hyadent gel (BioScience Gmbh, Ransbach-Baumbach, Germany), contained sterile gel, packed in sterile blister packages of $1 \mathrm{ml}$ volume with blunt and angulated cannulas were used. The modified viscosity and short resorption time (6-11 hours) ensures complete absorption by the surrounding tissue.

\section{Each syringe composed of:}

Na-hyaluronate $(14.0 \mathrm{mg})$, sodium chloride $(6.9 \mathrm{mg})$ and water for injection $(1.0 \mathrm{ml})$.

\section{Methods}

\section{Pre-surgical phase}

\section{A. Initial periodontal therapy}

Oral hygiene instructions were given; scaling and root planning were done.

\section{B. Preliminary evaluation}

Each patient was investigated clinically and radiographically. All patients were subjected to a detailed history taking including: personal data, medical history and dental history. Local visual examination, palpation of the entire oral and paraoral tissues was done to ensure right selection of the patients, then the teeth to be extracted were evaluated.

Primary alginate impression taking for both arches and casting diagnostic study models to evaluate interarch relationship, interocclusal space that could accommodate the implant abutment and the future crown restoration both clinically and on the study model.
Orthopantomograms (OPG) were done for all the patients to detect bone quality, any lesions related to teeth that were extracted and approximation to important anatomical structures.

\section{Surgical guide construction}

Fabrication of surgical guide stent using primary model were done, this allowed for accurate core biopsy from the grafted sockets and accurate implant insertion.

\section{Prophylactic preoperative medication}

Preoperative oral antibiotic one hour before surgery was given Amoxicillin $\quad 875 \mathrm{mg} /$ clavulanic acid $125 \mathrm{mg}$ (Augmentin 1gm Tablets, Medical Union Pharmaceuticals (MUP), GlaxoSmithKline (gsk), Cairo, Egypt).

\section{Surgical phase}

$0.12 \%$ chlorohexidine gluconate mouth wash (Hexitol mouthwash, Arab drug company, Cairo, Egypt) was used to rinse for 30 seconds before operation.

All patients were operated under local anaesthesia with Ubistesin $^{\mathrm{TM}}$ forte (Articaine HCL with epinephrine 1:100,000, 3M ESPE, Seefeld, Germany), atraumatic extraction was performed using periotome, to preserve the available alveolar bone bilaterally. Full thickness triangular flap extended from the distal surface of the mandibular first molar to the retro molar area was elevated for harvesting autogenous bone graft with auto-max from the external oblique ridge area (buccal shelf of bone) from only one side of the jaw. Auto-max bone harvester connected with its stopper, mounted on dental engine's handpiece at $290 \mathrm{rpm}$ with irrigation. While drilling, the stopper is pushed back so the bone can be extracted up to $4 \mathrm{~mm}$ at one area. As recommended by the manufacturer, to extract good quality of bone in chip form, only drilling $4 \mathrm{~mm}$ of cortical part at one location then moving to another location until the desired amount of bone has been collected according to extraction sockets sizes.

Bone graft particulates were collected from the bone harvester, then placed and secured in the empty socket with Hyadent gel in the study group and only bone graft in the control group and then both sockets were sutured Fig. (1).

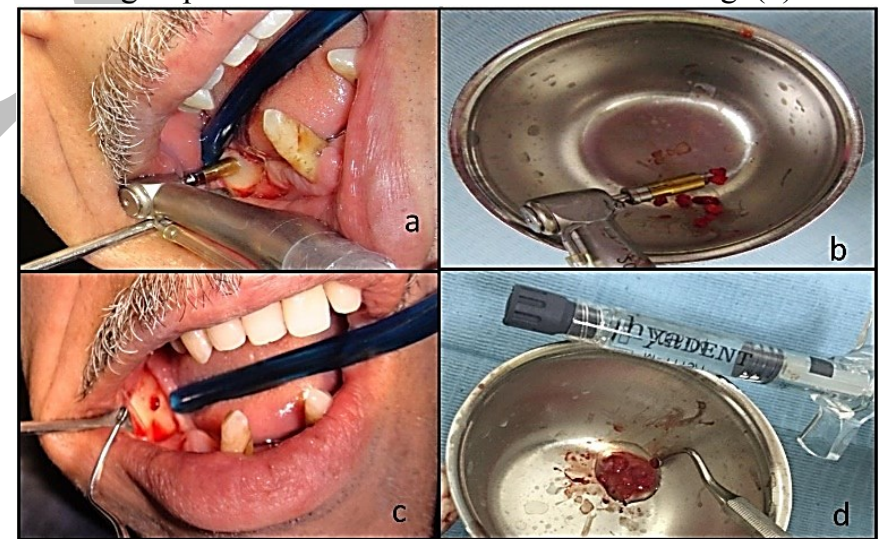

Figure 1: a. Bone harvesting with Auto-max bone harvester from external oblique ridge, b. Bone graft particulates within Auto-max bone harvester, $\mathrm{c}$. The harvesting site after collecting bone graft, $\mathrm{d}$. Autogenous bone graft ready to be applied in one of the extraction sockets with hyaluronic acid gel.

Surgical steps for core biopsies taking and implant placement after 2 months of healing:

For every patient, local anaesthesia was given. The stent was placed and core biopsies were taken without reflection of a flap using graded trephine bur (MCT, Korea) with $3 \mathrm{~mm}$ in diameter for later histological evaluation. 
The biopsied sockets were drilled using implant drills, performed as recommended by the manufacturer (Drilling speed was 800 RPM). Implants were inserted after drilling the implant bed using hand wrench and then finally seated down to full depth using ratchet wrench. Implant mounts were removed, smart pegs were attached with sizes corresponded to each implant size (Type 27 smart peg for the Green platform implants \& Type 32 smart peg for the Yellow platform implants), then; implants stability were assessed using OSSTELL ISQ (Goteborg, Sweden). Then, the cover screws derived in place.

\section{Postsurgical phase}

Postoperative instructions including: Extra - oral ice packs application intermittently every 10 minutes for 2 hours and maintain daily routine oral hygiene after surgery and Patients were instructed to eat a soft diet for 7 days .

All patients received Postoperative medications including:

- Broad spectrum oral antibiotics : Amoxicillin $875 \mathrm{mg} /$ Clavulanic acid 125mg (Augmentin 1gm Tablets, Medical Union Pharmaceuticals (MUP), GlaxoSmithKline, Cairo, Egypt) in a dose of one capsule every 12 hours for a week.

- Non-steroidal anti-inflammatory drugs Ibuprofen $400 \mathrm{mg}$ (Brufen tablet 400mg Abbott, Cairo, Egypt) at a dose of one tablet every 8 hours for four days.

- Warm chlorhexidine gluconate solution (Hexitol mouth wash, Arab Drug Co., Cairo, Egypt) as a mouthwash for a period of 2 weeks to enhance plaque control.

Sutures were removed one week postoperatively.

\section{III.Follow up phase}

\section{A. Clinical evaluation}

Early follow up: Was performed immediately after graft placement, at a period of 1 week to detect any Pain according to Numerical Rating scale from (0-10) (12).

After implant placement, each patient was evaluated clinically for:

1. Presence of pain or infection at a period of one week.

2. Peri-implant probing depth according to Glavind and Loe (13) on $3^{\text {rd }}$ and $6^{\text {th }}$ months.

3. Assessment of implant stability using OSSTELL immediately and on the $2^{\text {nd }}$ months after implant placement Fig. (2).

\section{B. Radiographic evaluation}

Digital standardized periapical $\mathrm{x}$-ray films with paralleling long cone technique by XCP film holder (XCP holder Rinn ${ }^{\mathrm{TM}}$, Dentsply International, York, PA, USA) for standardization of serial radiographs were done immediately and after 2 months of healing. To verify, Bone density changes in the grafted socket, by the aid of Image J software (Image J 1.50i; A public image processing domain software, National Institute of Health, Bethesda, Maryland, USA).

\section{Histological examination (15)}

All specimens were stained after fixation using hematoxylin and eosin (H\&E stain) to evaluate histologically the type, quality and quantity of formed bone.

\section{Histomorphometric analysis}

Computer-assisted histomorphometry were performed, to compare between the mean area percent filled by bone trabeculae in the two groups of bone augmentation.

\section{Prosthetic phase}

On the $3^{\text {rd }}$ month of implant placement, the final prosthesis was delivered over the abutments and functional loading was applied on the osseointegrated implants.

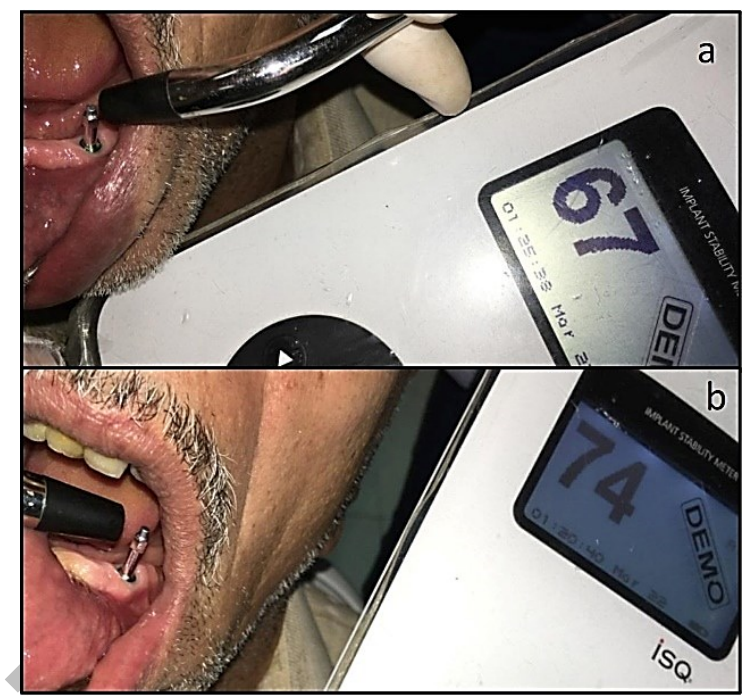

Figure 2: a. Primary implant stability immediately after implant insertion, b. Measuring ISQ after 2 months of implant placement.

STATISTICAL ANALYSIS OF THE DATA (16) Data were fed to the computer and analyzed using IBM SPSS software package version 20.0. (Armonk, NY: IBM Corp) (17) Qualitative data were described using number and percent. Quantitative data were described using range (minimum and maximum), mean, standard deviation and median. Significance of the obtained results was judged at the $5 \%$ level. The used tests were:

\section{Student t-test}

For normally quantitative variables, to compare between two studied groups.

\section{Paired t-test}

For normally quantitative variables, to compare between two periods.

\section{RESULTS}

Ten patients with bilateral carious mandibular single-rooted teeth indicated for extraction were involved in this study. Their ages ranged from 25 to 55 years with mean age of 42.4 years. The ratio between males and females was 2: 3 (four males and six females). Twelve implants were inserted in the canine region having diameters of $4.6 \mathrm{~mm}$ and length of $12.0 \mathrm{~mm}$. Eight implants were inserted in the lateral incisor region having diameters of 3.6 and lengths of $10.5 \mathrm{~mm}$ and $12.0 \mathrm{~mm}$.

All patients were followed up for six months and the results were registered as regards: clinical, radiographic evaluation, histological and histo-morphometric analysis.

\section{i. Clinical results}

After autogenous bone graft harvesting surgery and extraction procedures, all patients experienced mild to moderate pain at the surgical sites with mean pain severity 7 . The mean pain duration was $1.9 \pm 0.6$.

After implant placement procedures, all patients experienced mild to moderate pain at the surgical sites with mean pain severity 4 . The mean pain duration was $1.4 \pm$ 0.52 .

All patients continued the follow up period without any signs of infection, gingivitis, or peri-implantitis.

\section{Peri-implant probing depth:}

Probing depth was measured for all axial surfaces of all implants; statistical analysis of probing depth scores was done for all patients. Data collected were tabulated (Table 1) 
On the third month, the mean probing depth scores for the study group was $1.80 \pm 0.3 \mathrm{~mm}$ with a minimum recorded value of $1.5 \mathrm{~mm}$ and a maximum recorded value of 2.25 $\mathrm{mm}$, while the mean probing depth scores for the control group was $2.7 \pm 0.3 \mathrm{~mm}$ with a minimum recorded value of $2.5 \mathrm{~mm}$ and a maximum recorded value of $3.0 \mathrm{~mm}$. This difference in the probing depth score between the study and control groups was found to be statistically significant. $\left(\mathrm{P}_{2}=\right.$ $<0.001)$

On the sixth month, the mean probing depth scores for the study group was $1.30 \pm 0.4 \mathrm{~mm}$ with a minimum recorded value of $0.75 \mathrm{~mm}$ and a maximum recorded value of $2.0 \mathrm{~mm}$, while the mean probing depth scores for the control group was $2.0 \pm 0.3 \mathrm{~mm}$ with a minimum recorded value of $1.5 \mathrm{~mm}$ and a maximum recorded value of $2.5 \mathrm{~mm}$. This difference in the probing depth score between the study and control groups was found to be statistically significant. $\left(\mathrm{P}_{2}=0.001\right)$

The mean probing depth scores on the third and the sixth month within the same group (study and control) was found to be statistically significant. $\left(\mathrm{P}_{1}=0.001\right)$

Table 1: Comparison between the studied periods according to peri-implant probing depth.

\begin{tabular}{|l|c|c|c|c|}
\hline \multicolumn{1}{|c|}{$\begin{array}{c}\text { Peri-implant } \\
\text { probing depth }\end{array}$} & $3^{\text {rd }}$ month & $\mathbf{6}^{\text {th }}$ month & $\begin{array}{c}\text { Control (n= 10) } \\
3^{\text {rd }} \\
\text { month }\end{array}$ & $\begin{array}{c}6^{\text {th }} \\
\text { month }\end{array}$ \\
\hline Min. - Max. & $1.5-2.25$ & $0.75-2.0$ & $2.5-3.0$ & $1.5-2.5$ \\
Mean \pm SD. & $1.8 \pm 0.3$ & $1.3 \pm 0.4$ & $2.7 \pm 0.3$ & $2.0 \pm 0.3$ \\
Median & 1.8 & 1.4 & 2.5 & 2.0 \\
\hline $\mathbf{p}_{\mathbf{1}}$ & \multicolumn{3}{|c|}{$0.001^{*}$} & \multicolumn{2}{|c|}{$0.001^{*}$} \\
\hline $\mathbf{p}_{\mathbf{2}}$ & \multicolumn{3}{|c|}{$<0.001^{*}$} & $0.001^{*}$ \\
\hline
\end{tabular}

$\mathrm{p}_{1}$ : $\mathrm{p}$ value for Paired t-test for comparing between $3^{\text {rd }}$ month and $6^{\text {th }}$ month in each group

$\mathrm{p}_{2}: \mathrm{p}$ value for Student t-test for comparing between the two studied groups in each period

*: Statistically significant at $p \leq 0.05$

\section{Implant stability quotient (ISQ)}

A measurement of Osstell is displayed as implant stability quotient (ISQ) from 1 to 100 , where 100 signify the highest implant stability.

Immediately after implant placement, the mean ISQ value for the study group was $63.6 \pm 8.9$ with a minimum recorded value of 43.0 and a maximum recorded value of 72.0 , while the mean ISQ value for the control group was $65.0 \pm 4.78$ with a minimum recorded value of 56.0 and a maximum recorded value of 71.0. This difference in the implant stability quotient between the study and control groups immediately after implant placement was found to be statistically insignificant. $\left(\mathrm{P}_{2}=0.667\right)$

Two months later, the mean ISQ value for the study group was $75.1 \pm 6.74$ with a minimum recorded value of 60.0 and a maximum recorded value of 82.0 , while the mean ISQ value for the control group was $70.8 \pm 4.10$ with a minimum recorded value of 63.0 and a maximum recorded value of 76.0. This difference in the implant stability quotient between the study and control groups after two months of implant placement was found to be statistically insignificant. $\left(\mathrm{P}_{2}=0.102\right)$

The mean ISQ value immediately after implant placement and two months later within the same group (study and control) was found to be statistically significant. $\left(\mathrm{P}_{1}=<0.001\right)$

\section{ii. Radiographic results}

Bone densities were measured immediately after bone graft placement and after 2 month of healing in the previously preserved socket using:

Digital standardized periapical $x$-ray films analyzed by ImageJ computer software

Mean preserved socket bone density values recorded in pixels, tabulated and statistically analyzed (Table 2, Fig 3).

Immediately after bone graft placement, the mean bone density value for the study group was $74.44 \pm 6.37$ with a minimum recorded value of 67.18 pixels and a maximum recorded value of 86.22 pixels, while the mean bone density value for the control group was $72.77 \pm 3.97$ with a minimum recorded value of 67.07 pixels and a maximum recorded value of 78.17 pixels. This difference in bone densities between the study and control groups immediately after bone graft placement was found to be statistically insignificant. $\left(\mathrm{P}_{2}=\right.$ 0.492).

Table 2: Comparison between the two studied groups according to bone densities recorded from digital standardized periapical $\mathrm{x}-$ ray films analyzed by Image $\mathrm{J}$.

\begin{tabular}{|c|c|c|c|c|}
\hline \multirow[b]{2}{*}{$\begin{array}{l}\text { Digital } \\
\text { standardized per } \\
\text { apical x-ray films }\end{array}$} & \multicolumn{2}{|c|}{ Study $(n=10)$} & \multicolumn{2}{|c|}{ Control $(n=10)$} \\
\hline & $\begin{array}{c}\text { Immediately } \\
\text { after bone graft } \\
\text { placement }\end{array}$ & $\begin{array}{c}2 \\
\text { months } \\
\text { later }\end{array}$ & $\begin{array}{l}\text { Immediately } \\
\text { after bone } \\
\text { graft } \\
\text { placement }\end{array}$ & $\begin{array}{l}2 \text { months } \\
\text { later }\end{array}$ \\
\hline Min. - Max. & $67.18-86.22$ & $\begin{array}{c}81.05- \\
93.63\end{array}$ & $67.07-78.17$ & $70.12-85.05$ \\
\hline Mean \pm SD & $74.44 \pm 6.37$ & $\begin{array}{c}86.96 \pm \\
3.41\end{array}$ & $72.77 \pm 3.97$ & $79.23 \pm 4.07$ \\
\hline Median & 73.46 & 86.98 & 73.11 & 80.28 \\
\hline $\mathbf{p}_{1}$ & \multicolumn{2}{|l|}{$<0.001^{*}$} & \multicolumn{2}{|c|}{$0.009^{*}$} \\
\hline $\mathbf{p}_{2}$ & & & 0.492 & $<0.001^{*}$ \\
\hline
\end{tabular}

$\mathrm{p}_{1}$ : $\mathrm{p}$ value for Paired t-test for comparing between immediately after bone graft placement and 2 months later in each group

$\mathrm{p}_{2}$ : $\mathrm{p}$ value for Student t-test for comparing between the two studied groups in each period

*: Statistically significant at $\mathrm{p} \leq 0.05$

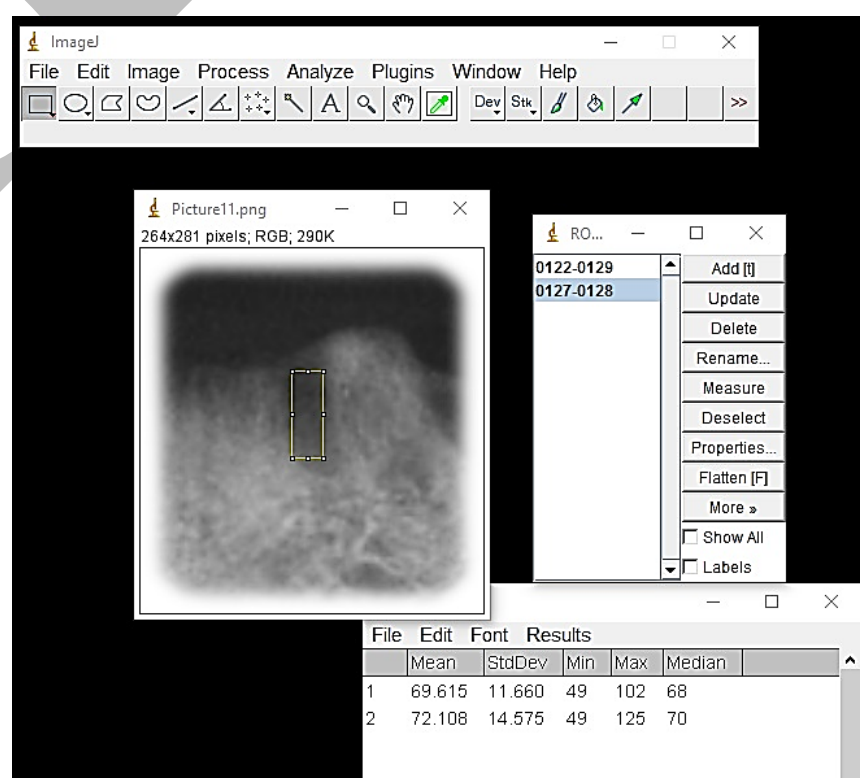

Figure 3: Measuring bone density in pixels using image $\mathrm{J}$ software from a digital peri-apical radiograph.

Two months later, the mean bone density value for the study group was $86.96 \pm 3.41$ with a minimum recorded value of 81.05 pixels and a maximum recorded value of 93.63 pixels, while the mean bone density value for the control group was 
$79.23 \pm 4.07$ with a minimum recorded value of 70.12 pixels and a maximum recorded value of 85.05 pixels. This difference in bone densities between the study and control groups after two months of bone graft placement was found to be statistically significant. $\left(\mathrm{P}_{2}=<0.001\right)$.

The mean bone density value immediately after bone graft placement and Two months later within the same group (study and control) was found to be statistically significant. ( $\mathrm{P}_{1}=$ $<0.001 \& 0.009$ respectively).

\section{Histological results}

For the control group, the histological examination of specimens showed small bone trabeculae bordered with osteoblasts and osteocytes within it. The trabeculae connected together and surrounding large spaces filled with fine fibers, cells and blood vessels. (Fig 4).

While in the study group, the histological examination of slices showed thick bone deposition which connected together replacing a large area of connective tissue. The thick bone trabeculae showed many interconnected resting parallel lines indicating rapid deposition with many well organized osteocytes as well as osteoblast lining of the bone surfaces. (Fig 5).

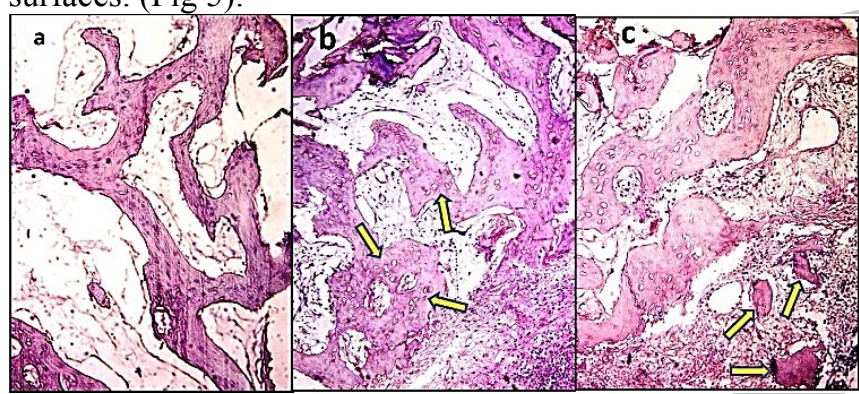

Figure 4: A photomicrograph $(\mathrm{PhM})$ of the control group showing: a. thin bone trabeculae joined together to replace the connective tissue around it, $b$. numerous canaleculei of osteocytes (as shown in arrows) with the connected bone trabeculae with still large spaced areas in between, c. large spots of woven bone formed within the connective tissue, which are not connected yet(arrow), while the connected trabeculae showed larger area with many osteocytes lacunae (H\&E stain x100).

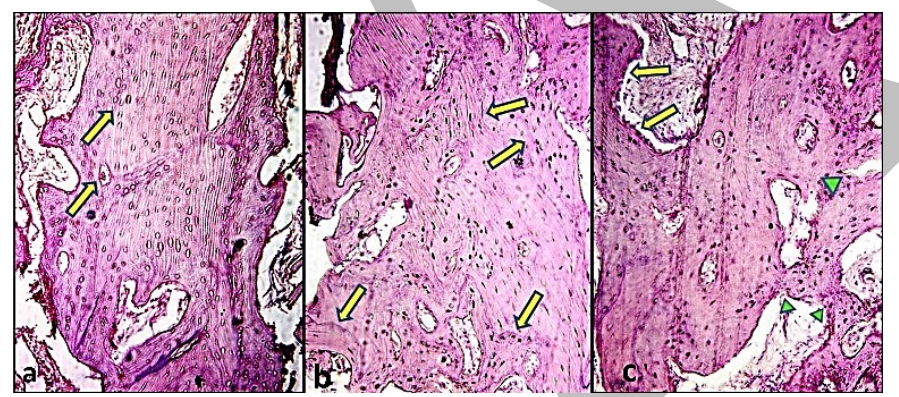

Figure 5: A photomicrograph (PhM) of the study group showing: a. thick bone trabeculae formed with many osteocytes lacunae within it (arrows). Note reduced size of the interspaces, b. well organization of the numerous osteocytes within thick bone trabeculae formed with many resting lines with very small spaced areas left (arrows), c. osteoblasts bordering bone surfaces (arrows) and many osteocytes within thick bone trabeculae connected together (arrow heads) and reduces the spaces in-between (H\&E stain $\mathrm{x} 100)$.

Histomorphometric estimation of the mean area percent filled by bone trabeculae was carried out, Using the Image $\mathrm{J}$ software on computer, all image of all slices were analyzed, data collected and statistically analyzed (Table 3, Fig 6).
In the study group, the mean area percent filled by bone trabeculae was found to be $90.59 \pm 2.32$ with a minimum recorded percentage of $87.30 \%$ and a maximum recorded percentage of $94.38 \%$, while the mean area percent filled by bone trabeculae in the control group was found to be $77.90 \pm 3.50$ with a minimum recorded percentage of 72.22 $\%$ and a maximum recorded percentage of $83.21 \%$. This difference in bone trabeculae percent between the study and control groups was found to be statistically significant. $(\mathrm{P}=$ $<0.001)$.

Table 3: Value of area \% filled by bone trabeculae among the studied groups.

\begin{tabular}{|l|c|c|c|c|}
\hline $\begin{array}{c}\text { Morphometric } \\
\text { analysis }\end{array}$ & $\begin{array}{c}\text { Study } \\
(\mathbf{n = 2 0})\end{array}$ & $\begin{array}{c}\text { Control } \\
(\mathbf{n = 2 0})\end{array}$ & $\mathbf{t}$ & $\mathbf{p}$ \\
\hline \multirow{2}{*}{ Min. - Max. } & $\begin{array}{c}87.30- \\
94.38\end{array}$ & $\begin{array}{c}72.22- \\
83.21\end{array}$ & & \\
\cline { 1 - 2 } Mean \pm SD. & $\begin{array}{c}90.59 \pm \\
2.32\end{array}$ & $\begin{array}{c}77.90 \pm \\
3.50\end{array}$ & \multirow{2}{*}{$13.512^{*}$} & $<0.001^{*}$ \\
\cline { 1 - 3 } Median & 91.10 & 78.16 & & \\
\hline
\end{tabular}

t: $t$ value for Student t-test

$\mathrm{p}$ : $\mathrm{p}$ value for comparing between the two studied groups

*: Statistically significant at $\mathrm{p} \leq 0.05$

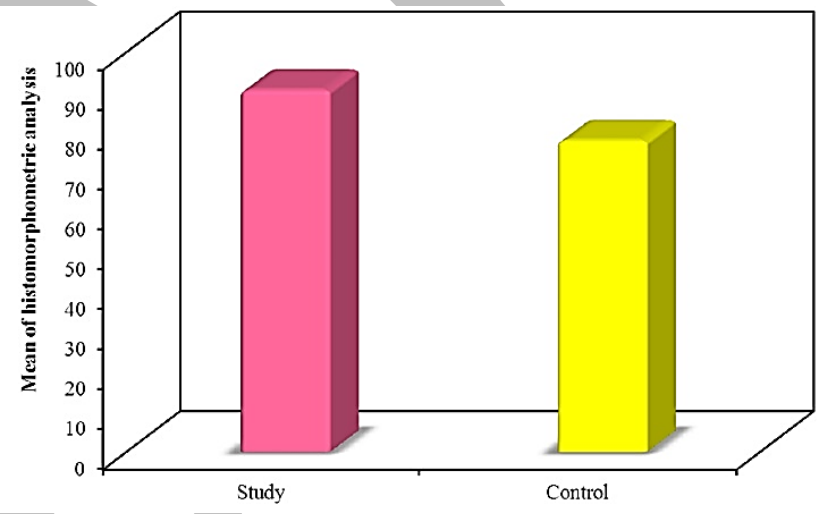

Figure 6: Value of area \% filled by bone trabeculae among the studied groups

\section{DISCUSSION}

In the present study, there were several reasons to consider preservation of the alveolar socket immediately following tooth extraction. One reason for placing a graft is to stabilize the coagulum within the socket and avoid possible reduction of the hard tissue volume required for bone regeneration. Another reason for placing a graft into an extraction socket was to provide a scaffold for the in growth of cellular and vascular components to form new bone of acceptable quality and quantity, and this was in accordance with Brkovic et al (18).

Autogenous bone has osteogenic potential, as it contains cells that participate in osteogenesis. Moreover, autografts are bioabsorbable and non-allergenic. Rapid revascularization occurs around autogenous bone graft particles, and the graft can release growth and differentiation factors $(6,19,20)$.

In the present study, the mean area percent filled by bone trabeculae when HyA was added to the autogenous bone in the extraction sockets, was found to be markedly higher in comparison to the control group when only the autogenous bone graft were used alone. This agreed with ELkarargy (21).

Ballini et al. (22) analyzed the osteoinductive effect of hyaluronic acid as an adjuvant in the grafting processes to 
produce bone-like tissue, employing autologous bone obtained from intraoral sites, to treat intrabony defects without covering membrane, in 9 patients. The clinical results showed an average increase in clinical attachment and suggest that autologous bone combined with hyaluronic acid seems to have good capabilities in accelerating new bone formation in the intrabony defects.

From a histological point of view, low molecular weight hyaluronic acid allowed bone regeneration in shorter time when it is used only with autologous bone graft, with important benefits for the clinical situation because it minimizes the period of time maintained after bone grafts for healing. And this also agreed with Baldini (23).

Zaffe and D'Avenia (9) confirmed that bone harvesting with a manual collector achieves good clinical success in extraction socket healing mixed with hyaluronic acid which, as confirmed by histologic evaluations, allows a better and faster healing process.

As for bone density evaluation, the current work revealed statistically significant difference between the two groups when bone density changes were evaluated using radiographic analysis by image $\mathrm{J}$ computer software immediately after bone graft placement with or without hyaluronic acid and then after two months of healing.

All included patients were subjected to delicate surgery using the delayed surgical placement and loading protocols. As low speed high torque hand piece was used for the preparation of the implant bed, and the drilling was performed under irrigation using cold normal saline for proper cooling and to avoid overheating of the bone tissue which would compromise osseointegration. This was spported by Strbac et al (24).

As for the peri-implant probing depth (PPD), the study group showed lower probing depth values than the control group, but both the study and control group showed statistically significant differences between the 3rd and 6th month postoperatively. This agreed with De Araújo Nobre et al. (25). During the course of their study found that HyA produced good results in maintaining a healthy peri-implant complex in immediate function implants for complete rehabilitations in the edentulous mandible. This also agrees with Wanden Bogaerde work (26) who analyzed 19 deep periodontal defects. One year after the treatment, the average PPD has been reduced to $5.8 \mathrm{~mm}$, gingival recession increased to $2.0 \mathrm{~mm}$ and the attachment increase was to $3.8 \mathrm{~mm}$, using esterified hyaluronic acid.

Regarding the implant mobility, no clinical mobility was detected in any of implants throughout the follow up period, as this considered as one of the most important criteria for implant success in accordance with Roos et al (27).

In the present study, comparison between the two studied groups revealed no statistically significant difference concerning the implant stability quotient intra-operatively and 2 months postoperatively. But it was statistically significant within the same group for both groups. However, Lai et al (28) found that the primary stability to be affected by bone type.

The application of tapered implants and progressive lateral bone compression during drilling are thought to improve the implant to bone contact, implant stability, and osseointegration (29).

Meredith (30) and Sennerby and Meredith (31) were first to propose RFA as a highly effective qualitative method to assess implant stability. Huang et al (32) evaluated implant behavior in different types of bones and confirmed the reliability of RFA in stability assessment.

\section{CONCLUSIONS}

Within the limitations of this study, the following conclusions can be addressed:

1. The use of autogenous bone graft with hyaluronic acid appears to be more efficient in osteoconduction when compared with autogenous bone graft alone and could be a promising strategy for preservation of alveolar sockets.

2. From the clinical, radiographical and histological evaluations, acceleration of bone deposition activities and bone remodeling process due to the presence of hyaluronic acid, which can reduce the time required for bone regeneration when associated with autologous cortical bone.

3. The difference in the ISQ between the study and control groups immediately after implant placement and after two months of implant placement was found to be statistically insignificant, which means that the primary stability of the implants was not affected till the second months by the hyaluronic acid when mixed with autogenous bone graft.

\section{CONFLICT OF INTREST}

The authors declare that they have no conflicts of interest.

\section{REFERENCES}

1. Quinn JH, Kent JN. Alveolar ridge maintenance with solid nonporous hydroxylapatite root implants. Oral Surg Oral Med Oral Pathol. 1984; 58:511-21.

2. Kentros GA, Filler SJ, Rothstein SS. Six-month evaluation of particulate Durapatite in extraction sockets for the preservation of the alveolar ridge. Implantologist. 1985; 3:53-62.

3. Hoexter DL. Osseous regeneration in compromised extraction sites: a ten-year case study. J Oral Implantol. 2002; 28:19-24.

4. Henkel KO, Gerber T, Lenz S, Gundlach KK, Bienengräber $\mathrm{V}$. Macroscopical, histological, and morphometric studies of porous bone- replacement materials in minipigs 8 months after implantation. Oral Surg Oral Med Oral Pathol Oral Radiol Endod. 2006; 102:606-13.

5. Ashman A. Postextraction ridge preservation using synthetic alloplast. Implant Dent. 2000; 9:168-76.

6. Marx RE. Clinical application of bone biology to mandibular and reconstruction. Clin Plast Surg. 1994; 21:377-84.

7. Urist MR. Bone: formation by autoinduction. Science. 1965; 150:893-9. "Quotation"

8. Widmark G, Ivanoff CJ. Augmentation of exposed implant threads with autogenous bone chips: prospective clinical study. Clin Implant Dent Relat Res. 2000; 2:178-83.

9. Zaffe D, D’Avenia F. A novel bone scraper for intraoral harversting:a device for filling small bone defects. Clin Oral Impl Res. 2007; 18:525-33.

10. Nandi A, Estess P,Siegelman MH. Hyaluronan Anchoring and Regulation on the Surface of Vascular Endothelial is Mediated through the Functionally Active Form of CD44. J Biol Chem 2000; 275: 14939-48. 
11. Sasaki T, Watanabe C. Stimulation of osteoinduction in bone wound healing by high-molecular hyaluronic acid. Bone. 1995; 16:9-15.

12. McCaffery M, Beebe A. Pain: Clinical Manual for Nursing Practice. London: Mosby; 1993. p 16.

13. Glavind L, Loe H. Errors in the clinical assessment of periodontal destruction. J. of Period. Res. 1967; 2:180-184.

14. Steflik DE, Koth DL, Robinson FG, McKinney RV, Davis $\mathrm{BC}$, Morris $\mathrm{CF}$. et al. Prospective investigation of the single-crystal sapphire endosteal dental implant in humans: ten-year results. J Oral Implant. 1995; 21:8-18.

15. Orban B, Bhaskar S. Oral histology and embryology. 13th ed. St. Louis: Mosby Company; 2011. pp 410-6.

16. Kotz S, Balakrishnan N, Read CB, Vidakovic B. Encyclopedia of statistical sciences. 2nd ed. Hoboken, N.J.: Wiley-Interscience; 2006.

17. Kirkpatrick LA, Feeney BC. A simple guide to IBM SPSS statistics for version 20.0. Student ed. Belmont, Calif.: Wadsworth, Cengage Learning; 2013.

18. Brkovic BM, Prasad HS, Konandreas G, Milan R, Antunovic D, Sándor GK, et al. Simple preservation of a maxillary extraction socket using beta-tricalcium phosphate with type I collagen: preliminary clinical and histomorphometric observations. J Can Dent Assoc. 2008; 74:523-8.

19. Kim CS, Choi SH, Cho KS, Chai JK, Wikesjö UM, Kim CK. Periodontal healing in one wall intra-bony defects in dogs following implantation of autogenous bone or a coralderived biomaterial. J Clin Periodontol. 2005; 32:583-9.

20. MacNeill SR, Cobb CM, Rapley JW, Glaros AG, Spencer P. In vivo comparison of synthetic osseous graft materials. A preliminary study. J Clin Periodontol. 1999; 26:239-45.

21. ELkarargy A. Alveolar Sockets Preservation Using Hydroxyapatite / Beta tricalcium Phosphate with Hyaluronic Acid (Histomorphometric study). J Am Sci. 2013; 9:556-63.

22. Ballini A, Cantore S, Capodiferro S, Grassi FR. Esterified hyaluronic acid and autologous bone in the surgical correction of the infra-bone defects. Int J Med Sci. 2009; $6: 65-71$.

23. Baldini A, Zaffe D, Nicolini G. Bone-defects healing by high-molecular hyaluronic acid: Preliminary results. Ann Stomatol (Roma) 2010; 1:2-7.

24. Strbac GD, Unger E, Donner R, Bijak M, Watzek G, Zechner W. Thermal effects of a combined irrigation method during implant site drilling. A standardized in vitro study using a bovine rib model. Clin Oral Implants Res. 2012; 25:665-74.

25. De Araújo Nobre M, Cintra N, Maló P. Peri-implant maintenance of immediate function implants: A pilot study comparing hyaluronic acid and chlorhexidine. Int $\mathrm{J}$ Dent Hyg. 2007; 5:87-94.

26. Wanden Bogaerde L.Treatment of infrabony periodontal defects with esterified hyaluronic acid: Clinical report of 19 consecutive lesions. Int J Periodontics Restorative Dent. 2009; 29:315-23.

27. Roos J, Sennerby L, Lekholm U, Jemt T, Grondahl K, Albrektsson T. A qualitative and quantitative method for evaluating implant success: a 5-year retrospective analysis of the Branemark implant. Int J Oral Maxillofac Implants. 1997; 12:504-14.

28. Lai HC, Zhuang LF, Zhang ZY. Stability of implants placed in different bone types. Zhonghua Kou Qiang Yi Xue Za Zhi. 2007; 42:292-3.
29. Petrie CS, Williams JL. Comparative evaluation of implant designs: influence of diameter, length, and taper on strains in the alveolar crest - a three-dimensional finite-element analysis. Clin Oral Implants Res. 2005; 16:486-94.

30. Meredith N. Assessment of implant stability as a prognostic determinant. Int J Prosthodont. 1998; 11:491-501.

31. Sennerby I, Meredith N. Resonance frequency analysis: measuring implant stability and osseointegration. Compend Contin Educ Dent. 1998; 19:493-8,500,502; quiz 504.

32. Huang HM, Lee SY, Yeh CY, Lin CT. Resonance frequency assessment of dental implant stability with various bone qualities: a numerical approach. Clin Oral Implants Res. 2002; 13:65-74.

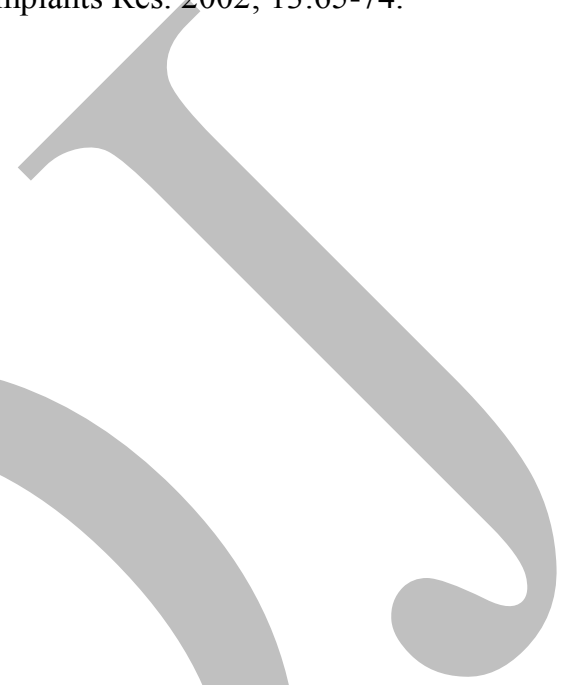

